\title{
Evaluation of Sorbents for Acetylene Separation in Atmosphere Revitalization Loop Closure
}

\author{
Morgan B. Abney ${ }^{1}$ \\ NASA Marshall Space Flight Center, Huntsville, AL, 35812 \\ Lee A. Miller ${ }^{2}$ \\ ECLS Technologies, LLC., Huntsville, AL, 35802 \\ and \\ Katherine Barton ${ }^{3}$ \\ University of Alabama, Tuscaloosa, AL, 35487
}

\begin{abstract}
State-of-the-art carbon dioxide reduction technology uses a Sabatier reactor to recover water from metabolic carbon dioxide. In order to maximize oxygen loop closure, a byproduct of the system, methane, must be reduced to recover hydrogen. NASA is currently exploring a microwave plasma methane pyrolysis system for this purpose. The resulting product stream of this technology includes unreacted methane, product hydrogen, and acetylene. The hydrogen and the small amount of unreacted methane resulting from the pyrolysis process can be returned to the Sabatier reactor thereby substantially improving the overall efficiency of the system. However, the acetylene is a waste product that must be removed from the pyrolysis product. Two materials have been identified as potential sorbents for acetylene removal: zeolite $4 \mathrm{~A}$, a commonly available commercial sorbent, and HKUST-1, a newly developed microporous metal. This paper provides an explanation of the rationale behind acetylene removal and the results of separation testing with both materials.
\end{abstract}

\section{Nomenclature}

$\mathrm{CH}_{4}=$ Methane

$C M=$ Crew Member

$\mathrm{CO}_{2}=$ Carbon Dioxide

$C R A=$ Carbon Dioxide Reduction Assembly

$M S F C=$ Marshall Space Flight Center

$O G A=$ Oxygen Generation Assembly

$P C I=$ Precision Combustion, Inc.

$P P A \quad=$ Plasma Pyrolysis Assembly

$Q M S \quad=$ Quadrapole Mass Spectrometer

VVS = Venturi Vacuum System

$\mu G C=$ Micro-Gas Chromatograph

\section{Introduction}

T HE Carbon Dioxide $\left(\mathrm{CO}_{2}\right)$ Reduction Assembly (CRA) aboard the International Space Station involves the use of a Sabatier reactor to convert metabolic $\mathrm{CO}_{2}$ to water and methane $\left(\mathrm{CH}_{4}\right)$. The water product is condensed and sent to the Oxygen Generation Assembly (OGA) where it is electrolyzed to provide oxygen to the crew. The

1 NASA Atmosphere Revitalization Loop Closure Lead, Environmental Control and Life Support Systems Development Branch, MSFC ES62, Huntsville, AL, 35812, AIAA Member.

${ }^{2}$ Test Engineer, Environmental Control and Life Support Systems Development Branch, Bldg 4755 Room 103A, Huntsville, AL 35812, AIAA Senior Member.

${ }^{3}$ Spring 2011 Undergraduate Student Research Program Intern, University of Alabama, Tuscaloosa, AL 35487. 
secondary OGA product, hydrogen, is then used by the CRA to reduce additional $\mathrm{CO}_{2}$. The methane product from the CRA is currently vented overboard as a waste product. However, for long-term missions, the hydrogen bound in methane molecules must be recovered to maximize $\mathrm{CO}_{2}$ reduction in the CRA. For this purpose, NASA is currently exploring the Plasma Pyrolysis Assembly (PPA).

PPA hardware at Marshall Space Flight Center (MSFC) was developed by UMPQUA Research Company ${ }^{1}$ and tested at MSFC. ${ }^{2}$ During this testing, the PPA was integrated with a CRA development unit and showed promising results. If used in flight, the PPA has the potential to increase oxygen recovery by more than $300 \mathrm{lbm}$ per crew member (CM) per year, beyond CRA alone. This will effectively save approximately $350 \mathrm{lbm}$ of water resupply per $\mathrm{CM}$ per year. At a launch cost of $\$ 10,000.00$ per lbm, this results in a potential savings of $\$ 14$ million per year for a crew of four. However, in order for the PPA to be effectively integrated with a CRA, PPA product hydrogen must be recycled back to the CRA. In addition to product hydrogen and acetylene, the PPA contains un-reacted methane in the product stream. Thus, a separation system must be used downstream of the PPA.

There are numerous methods of separating hydrogen from a gas stream. Among the most mature of these are membrane separations, cryogenic separations, and sorbent-based separations. Membrane separations invariably require a pressure differential across the membrane. Many commercially available units require a differental of at least 2585 torr (50 psid). The PPA operates at 50 torr. To use a membrane separation system, the PPA product gas would need to be pressurized. This is a concern for two reasons. First, acetylene becomes increasingly unstable above atmospheric pressure. Spontaneous decomposition of acetylene, and the subsequent release of energy (explosion), poses a serious safety hazard. Second, pressurizing a gas from 50 torr ( 1 psi) to more than 3300 torr ( $65 \mathrm{psi})$ would require a high power compressor as well as accumulators. Thus, membrane separation is not preferred for this application. Cryogenic separations will require a cryogenic source to maintain temperatures. Cryogenic cooling lines are not necessarily going to be readily available on future missions. To make cryogenic cooling available solely for this purpose would prohibitively increase the power requirements of the system. Sorbent-based separations are the most desirable option for multiple reasons. First, NASA has extensive experience using sorbent-based systems, particularly for life support $\mathrm{CO}_{2}$ removal technology. Second, many sorbents can be regenerated at moderate temperatures or simply vacuum, allowing for low-power systems. Finally, adsorption to sorbents can be completed below atmospheric pressure, providing a system safe enough for acetylene. Thus, for a PPA separation system, sorbent-based separation was chosen for further development.

In previous stand-alone testing, the PPA product stream contained 1-6\% methane, $86-89 \%$ hydrogen, and 5-8\% acetylene (mol \%). Due to the hazardous nature of acetylene it is most advantageous to remove acetylene from the PPA product stream. If methane is removed from the product stream, it would be vented as a waste product. This ultimately reduces the recoverable oxygen due to the loss, albiet small, of hydrogen bound in methane. If methane is not removed, it will be recycled to the CRA along with hydrogen. This recycle stream will then contain up to $6 \%$ methane. No previous studies have been completed to determine the effect of methane in the CRA hydrogen feed. It is expected to decrease the total conversion of $\mathrm{CO}_{2}$ in the system due to the equilibrium design of the reactor.

Two sorbents have been identified for acetylene adsorption. The first, zeolite $4 \mathrm{~A}$, has been shown to readily adsorb acetylene at a wide range of pressures and temperatures $\left(\sim 4.9 \mathrm{mmol} / \mathrm{g} 4 \mathrm{~A}\right.$ at $273 \mathrm{~K}$ and 400 torr). ${ }^{3}$ Zeolite aggregates were prepared from $4 \mathrm{~A}$ powder and tested with a variety of gases. Methane showed very low adsorption $(0.7 \mathrm{mmol} / \mathrm{g} 4 \mathrm{~A}$ at $273 \mathrm{~K}$ and 400 torr). $\mathrm{CO}_{2}$ was the only gas that showed similar adsorption capacity to acetylene. However, because there is no

Table 1. Literature values for uptake of various gases on HKUST-1. All data were taken at $295 \mathrm{~K}$ and latm with the exception of sulfur dioxide which was taken at $473 \mathrm{~K}$ at latm. All values were approximately determined from literature graphs.

\begin{tabular}{|l|c|}
\multicolumn{1}{|c|}{ Challenge Species } & $\begin{array}{c}\text { Uptake (mmol/g } \\
\text { HKUST-1) }\end{array}$ \\
\hline Propane $^{5}$ & 6.8 \\
\hline Propylene $^{5}$ & 7.8 \\
\hline n-Isobutane & 6.0 \\
\hline Sulfur Dioxide $^{6}$ & 0.1 \\
\hline Carbon Dioxide & 4.2 \\
\hline Methane $^{7}$ & 0.8 \\
\hline Nitrogen $^{7}$ & 0.3 \\
\hline Oxygen $^{7}$ & 0.2 \\
\hline Nitrous Oxide $^{7}$ & 3.8 \\
\hline Ethylene $^{7}$ & 5.9 \\
\hline Ethane $^{7}$ & 4.8 \\
\hline Acetylene $^{8}$ & $\mathbf{8 . 7}$ \\
\hline
\end{tabular}
$\mathrm{CO}_{2}$ in the PPA outlet stream, 4A shows considerable potential as an acetylene separation sorbent. The second sorbent, HKUST-1, was originally developed in 1999 by Chui, et al. ${ }^{4}$ Since that time, HKUST-1 has been challenged with a number of different gases. Table 1 provides a summary of these studies and the resulting quantities of adsorbed species. HKUST-1 has also been studied as a possible hydrogen storage medium. ${ }^{9-10}$ However, these studies explored hydrogen adsorption at cryogenic temperatures. Hydrogen uptake has been shown to be negligible at ambient temperature and pressure. Thus, based on the low 
uptake of hydrogen and methane, and the significant adsorption of acetylene on HKUST-1, the material has significant potential for a PPA separation system.

The purpose of this effort was to explore the use of zeolite 4A and HKUST-1 for acetylene separation from methane and hydrogen as produced by the PPA. Additionally, an effort was made to determine the effect of methane in the hydrogen-feed to the SDU, in the event the PPA recycle stream contains unreacted methane. This paper details the preparation of sorbent beds, testing methods, testing results, and a discussion of findings.

\section{Hardware Description}

Hardware used for the majority of this testing includes the separation test stand and three separate sorbent beds. Each are described below. Additionally, a Sabatier Development Unit (SDU) built by Hamilton Sundstrand was used for a small portion of the testing. The system was described in detail previously, ${ }^{2}$ and will be described only briefly here.

\section{A. Separation Test Stand}

The separation test stand can be seen schematically in Figure 1. The system is composed of the PPA, the sorbent Bed Assembly, a Venturi Vacuum System (VVS), a Data Acquisition system, and two systems for gas analysis including a Stanford Research Systems Quadrapole Mass Spectrometer (QMS), and an Agilent Technologies microGas Chromatograph $(\mu \mathrm{GC})$. Additionally, the system includes various flowmeters, thermocouples, pressure transducers, etc. for test stand operation.

The PPA, described elsewhere ${ }^{1-2}$, was used in all testing to generate challenge gas streams. Briefly, the PPA,

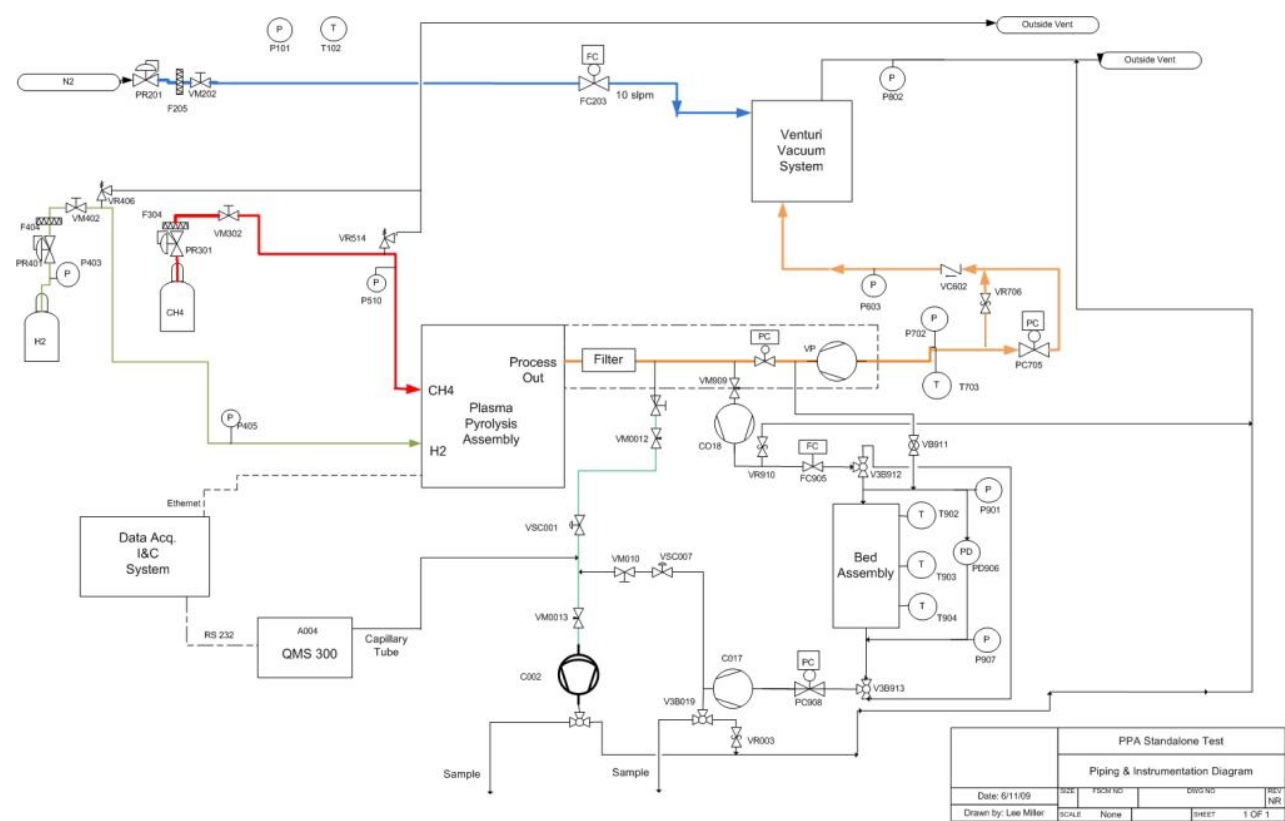

Figure 1. Separation test stand schematic. Bed Assembly design allows for interchangeable installation of sorbent beds as required for testing. uses microwave power to generate a hydrogen plasma. Methane is fed to the plasma and partially pyrolyzed to form hydrogen and acetylene gas. The system is maintained at 50 torr by a hydrogen-rated vacuum pump located within the PPA hardware. Hydrogen and methane are supplied to the PPA from locally placed kbottles.

The flexible design of the Bed Assembly allows for a variety of sorbent beds to be installed.

A partial stream of PPA effluent is fed to the Bed Assembly for separation testing. Three-way valves at the inlet and outlet of the Bed Assembly provide a bypass route, if desired. A pressure controller is located between the Bed Assembly outlet and the VVS to control the pressure inside the sorbent bed. When testing, the sorbent bed outlet can either be sent entirely to the VVS, entirely to gas analysis, or be split between the two to allow for both analysis and to control sorbent bed pressure. Each sorbent bed is equipped with its own heating system for regeneration.

The VVS provides a safe avenue for the PPA effluent stream to be exhausted. Methane, hydrogen, and acetylene are diluted with nitrogen in the VVS before being vented outside of the MSFC Test Facility.

The Data Acquistion system is controlled by an in-house program called PACRATS. Data from flow meters, pressure transducers, thermocouples, etc., is collected every second and stored for later analysis. 
The test assembly control software is based in LabView and programmed in-house. The software controls all components of the test stand with the exception of the PPA microwave power. This must be controlled by hand. However, the software monitors the microwave power level and provides warnings if off-nominal conditions are detected.

\section{B. Sorbent Beds}

Three sorbent beds were evaluated for this test. They included a zeolite 4A sorbent bed, an HKUST-1 sorbent bed, and a bed containing HKUST-1 Coated Microlith® prepared by Precision Combustion, Inc. Zeolite 4A beads were purchased from Delta Adsorbents (Roselle, IL) and used as delivered. HKUST-1 was purchased from Dr. Banglin Chen's Chemistry group at the University of Texas at San Antonio. Dr. Chen's team was the first to recognize the acetylene adsorption capacity of HKUST $-1 .{ }^{8}$ Each sorbent bed is described in detail below.

\section{Zeolite 4 A Sorbent Bed}

The zeolite 4A bed assembly, shown in Figure 2, was fabricated from $1.91 \mathrm{~cm}$ ID stainless steel tube and packed with commercially procured material in the form of $2.5 \mathrm{~mm}$ cylindrical beads. The packed volume has a length of $20.0 \mathrm{~cm}$ and contains $32.15 \mathrm{~g}$ of $4 \mathrm{~A}$ sorbent. The assembly incorporates thermocouples to monitor bed temperatures as well as heaters to allow controlled thermal regeneration. The bed assembly is enclosed within an insulated outer shell that allows controlled flow of cooled air over the packed bed assembly. The bed assembly interfaces with the test stand with standard 1/4 inch fittings to simplify installation and configuration.

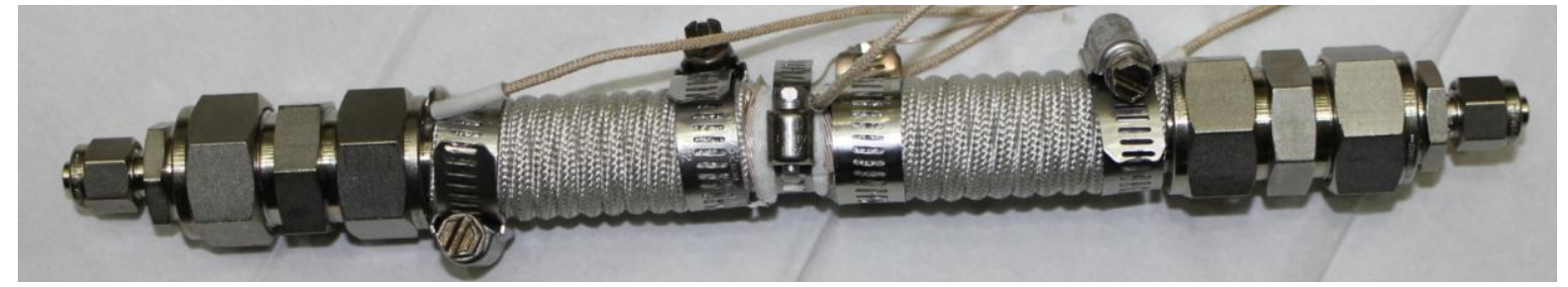

Figure 2. Zeolite 4A bed assembly. Assembly contains $32.15 \mathrm{~g}$ of $4 \mathrm{~A}$ sorbent.

\section{HKUST-1 Coated Microlith® Bed}

Due to the powdered form of HKUST-1, immobilization was of key interest for testing. For this purpose, Precision Combustion, Inc. (PCI) was contracted to coat HKUST-1 onto a mesh substrate using their patented Microlith ${ }^{\circledR}$ technology. HKUST-1-coated Microlith ${ }^{\circledR}$ screens can be seen in Figure 3 . The sorbent bed housing was fabricated at NASA per requirements provided by PCI. The resulting sorbent bed, shown in Figure 4, has a total volume of approximately $54 \mathrm{~mL}$ and contains approximately $6.5 \mathrm{~g}$ of HKUST-1. The Microlith® is contained in a stainless steel tube measuring approximately $5 \mathrm{~cm}$ long with a $3.8 \mathrm{~cm}$ inner diameter. Thermocouples were placed along the bed to monitor temperature, and a heat wrap was coiled around the housing to achieve thermal

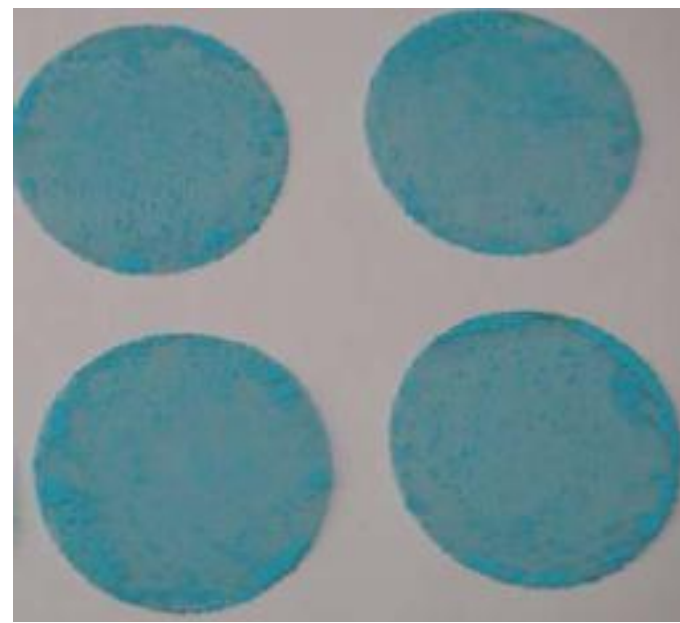

Figure 3. Microlith $®$ Screens coated with

HKUST-1. Photo courtesy of Precision Combustion, Inc.

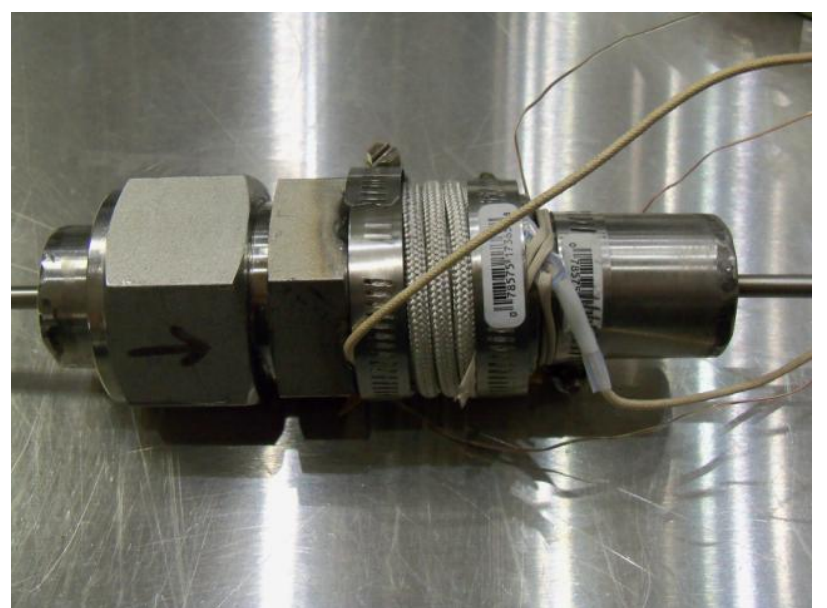

Figure 4. HKUST-1 Microlith ${ }^{\circledR}$ bed assembly. Assembly contains $\sim 6$ of HKUST-1 sorbent. 
regeneration temperatures. The housing was placed in an insulated outer shell to allow controlled flow of cooled air over the bed during testing. The housing tapers to a standard $1 / 4$ inch tube for installation into the test stand.

\section{HKUST-1 Packed Bed}

The HKUST-1 packed bed, shown in Figure 5, was fabricated with $1.91 \mathrm{~cm}$ ID stainless steel tube and packed with $45 \mu \mathrm{m}$ HKUST-1 spheres. A total quantity of $4.1 \mathrm{~g}$ HKUST-1 was packed between pieces of insulation and stainless steel 400 wire mesh to contain the sorbent. Thermocouples where placed along the bed assembly to monitor temperatures, and a heat wrap was placed around the assembly for thermal regeneration. The bed was enclosed within a insulated outer shell to allow controlled flow of cooled air over the bed during testing. The attached fittings taper down to standard $1 / 4$ inch fittings for test stand intergration.

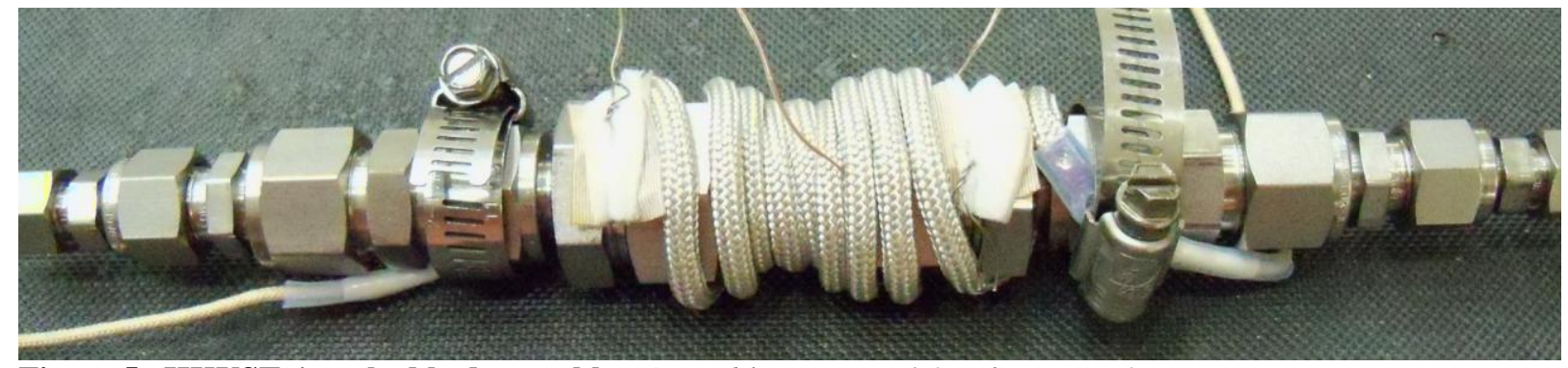

Figure 5. HKUST-1 packed bed assembly. Assembly contains $4.1 \mathrm{~g}$ of HKUST-1.

\section{Sabatier Development Unit}

The SDU is a stand-alone system capable of accepting hydrogen and $\mathrm{CO}_{2}$ for reaction over a ruthenium catalyst. The system provides the energy at the inlet of the reactor to start the Sabatier reaction. The remainder of the reactor is cooled to maximize equilibrium conversion of reactants. The SDU is composed of the reactor, a phase separator, and various components to allow for control and monitoring of the system. The system is controlled using Lookout Direct software prepared by Hamilton Sundstrand.

\section{Methods}

Acetylene separation was explored on three sorbent beds. Each bed was tested at 200, 400 and 600 Torr. The QMS system was operated continuously during all adsorption testing to provide composition of the gas stream exiting each bed. Temperature and pressure data were also taken during adsorption. The loading of acetylene onto the bed was calculated for each test run. The SDU was challenged with hydrogen feed streams containing small quantities of methane. Details for the testing of each bed and the SDU are provided below.

\section{A. 4A Sorbent Bed}

Previous literature indicated substantial adsorption of acetylene in zeolite $4 \mathrm{~A} .{ }^{3}$ For this reason, the first bed tested for acetylene adsorption contained 4A zeolite. The bed was tested at two flow rates including 100 and 500 SmLPM. Testing at 500 SmLPM was accomplished in three trials, each with a single repeat, as shown in Table 2. Testing at 100 SmLPM consisted of three trials with no repeats. Before each trial, a Full Regeneration at $250^{\circ} \mathrm{C}$ for 4 hours was performed, followed by cooling to sub-ambient temperature. During each trial, PPA effluent gasses were fed to the bed at the desired flow rate until complete breakthrough of acetylene was observed. Between each run, a Partial Regeneration was performed after breakthrough by applying vacuum at $125^{\circ} \mathrm{C}$ for 1 hour.

Table 2. Testing order and description for $4 \mathrm{~A}$ zeolite sorption bed.

\begin{tabular}{|c|c|c|c|c|}
\hline Trial & $\begin{array}{l}\text { Flow Rate } \\
\text { (SmLPM }\end{array}$ & Pressure & Runs & $\begin{array}{c}\text { Partial } \\
\text { Regenerations }\end{array}$ \\
\hline 1 & 500 & 600 Torr & 2 & 1 \\
\hline 2 & 500 & 200 Torr & 3 & 2 \\
\hline 3 & 500 & 600 Torr & 3 & 2 \\
\hline 4 & 500 & 400 Torr & 3 & 2 \\
\hline 5 & 500 & 400 Torr & 2 & 1 \\
\hline 6 & 500 & 200 Torr & 2 & 1 \\
\hline 7 & 100 & 200 Torr & 2 & 1 \\
\hline 8 & 100 & 600 Torr & 2 & 1 \\
\hline 9 & 100 & 400 Torr & 2 & 1 \\
\hline
\end{tabular}




\section{B. HKUST-1 Microlith ${ }^{\circledR}$ Sorbent Bed}

Xiang et al. previously reported extremely high quantities of acetylene adsorption on HKUST- $1 .{ }^{8}$ For this reason, the second bed tested for acetylene adsorption contained HKUST-1 sorbent obtained from the University of Texas at San Antonio. The bed was tested in three trials, each with a single repeat, as shown in Table 3. Before testing could occur, a one-time initial regeneration was performed at $125^{\circ} \mathrm{C}$ for 12 hours. Prior to each trial, a Full Regeneration at $125^{\circ} \mathrm{C}$ for 1 hour was performed, followed by cooling to sub-ambient temperature. During each trial, PPA effluent gasses were fed to the bed at 50 SmLPM until complete breakthrough of acetylene was observed. For each run, Partial Regeneration was performed after breakthrough and was conducted by applying vacuum at ambient temperature $\left(\sim 25^{\circ} \mathrm{C}\right)$ for 1 hour.

\section{HKUST-1 Packed Sorbent Bed}

A packed HKUST-1 bed was constructed and tested for two reasons. The first was to evaluate any negative effects of the techiniques used to immobilize the HKUST-1 on the Microlith ${ }^{\circledR}$. The second was to evaluate the HKUST-1 material for maximum performance in a large scale implementation. The bed was tested in three trials, as shown in Table 4. Before testing could occur, a one-time initial regeneration was performed at $150^{\circ} \mathrm{C}$ for 18 hours. Prior to each trial, a Full Regeneration at $125^{\circ} \mathrm{C}$ for 1 hour was performed, followed by cooling to sub-ambient temperature. During each trial, PPA effluent gasses were fed to the bed at 100 SmLPM until $90 \%$ breakthrough of acetylene was observed. Between each run, Partial Regeneration was performed after breakthrough and was conducted by applying vaccum at ambient temperature $\left(\sim 25^{\circ} \mathrm{C}\right)$ for 1 hour.

\section{SDU Modified Feed Stream Testing}

Because a hydrogen recycle stream from the PPA is expected to contain quantities of methane, it was necessary to test the effect of this methane on SDU performance. The SDU was operated with $\mathrm{a}_{2}$ feed rate equivelant to a crew of 4 (1.42 SLPM). The system was tested at $\mathrm{H}_{2}: \mathrm{CO}_{2}$ ratios of 3.5 (nominal), 4.0 (stoichiometric), and 5.5. For ratios of 3.5 and 4.0, methane was included in the stream at $0,2,4,6,8,10,12$, and $15 \mathrm{~mol} \%$. For a ratio of 5.5, the system was tested at $0,2,4,6,8$, and $10 \mathrm{~mol} \%$. Higher percentages were not possible for the 5.5 ratio due to the pressure limit of the system.

\section{Results and Discussion}

Acetylene adsorption was observed on three beds with each containing either 4A zeolite or HKUST-1. Although specific pressure and flow rates were targeted for each run, these values tended to vary by as much as $50 \%$ and $10 \%$, respectively. The SDU was tested using an off-nominal feed stream. Results of this testing are provided and discussed below.

\section{A. Acetylene Adsorption on Zeolite 4A Sorbent Bed}

Testing of the $4 \mathrm{~A}$ sorbent bed was conducted at flow rates of 500 and 100 SmLPM. Specific adsorption of acetylene at each pressure and flow rate is shown in Figure 6 . The graph provides a comparison of adsorbed acetylene (mmols) per gram of zeolite 4A. Data for each run is shown with values listed at the top of each column. For each pressure, trial values conducted at 500 SmLPM are shown in purple and trial values at 100 SmLPM are shown in
Table 3. Testing order and description for HKUST-1 Microlith ${ }^{\circledR}$ sorption bed.

\begin{tabular}{|c|c|c|c|}
\hline Trial & Pressure & Runs & $\begin{array}{c}\text { Partial } \\
\text { Regenerations }\end{array}$ \\
\hline 1 & 200 Torr & 3 & 2 \\
\hline 2 & 400 Torr & 3 & 2 \\
\hline 3 & 600 Torr & 3 & 2 \\
\hline 4 & 600 Torr & 3 & 2 \\
\hline 5 & 200 Torr & 3 & 2 \\
\hline 6 & 400 Torr & 3 & 2 \\
\hline
\end{tabular}

Table 4. Testing order and description for packed HKUST-1 bed.

\begin{tabular}{|c|c|c|c|}
\hline Trial & \multicolumn{1}{c|}{ Pressure } & \multicolumn{1}{c|}{ Runs } & \multicolumn{1}{c|}{$\begin{array}{c}\text { Partial } \\
\text { Regenerations }\end{array}$} \\
\hline 1 & 200 Torr & 3 & 2 \\
\hline 2 & 400 Torr & 3 & 2 \\
\hline 3 & 600 Torr & 3 & 2 \\
\hline
\end{tabular}


orange with progressive runs shown in darker shades. Error bars above the first and second runs at 500 SmLPM represent the standard deviation between the trial and its repeat. As seen from the data, acetylene adsorption was not shown to significantly decrease from run to run despite the Partial Regeneration performed between each run. The Full Regeneration protocol, performed between repeats and separate trials, appeared to result in complete regeneration of the sorbent material. In application, it may be possible to use the Partial Regeneration protocol for a given length of time before a Full Regeneration is required. This will allow for smaller sized sorbent beds, reduce power requirements, and possibly reduce the number of beds required for constant acetylene removal. As seen from the data, adsorption levels at 100 SmLPM were significantly lower than those at 500 SmLPM. Since only one trial was performed for the $100 \mathrm{SmLPM}$ data point, it is not clear why the lower flow rate showed lower adsorption. It is possible that the bed was not completely regenerated as originally believed or that the material was contaminated, or even that there was a problem with the calibration of the QMS. Additional testing must be conducted to explain this observation.

The composition of the sorbent bed exit stream was evaluated (in mole \%) using the QMS. Each pressure showed a distinct curve regardless of the amount of acetylene adsorbed. Figure 7 compares exit stream acetylene composition (mol\%) during adsorption at each pressure and flow rate. The adsorption data for each of these curves was taken from the first run of each of the six trials, although each run showed similar curves at a given pressure and flow rate. For the 500 SmLPM flowrate, complete adsorption of the acetylene in the feed stream was observed. This is seen in Figure 7 where the initial values shown by the curves are zero, meaning no acetylene was exiting the bed.

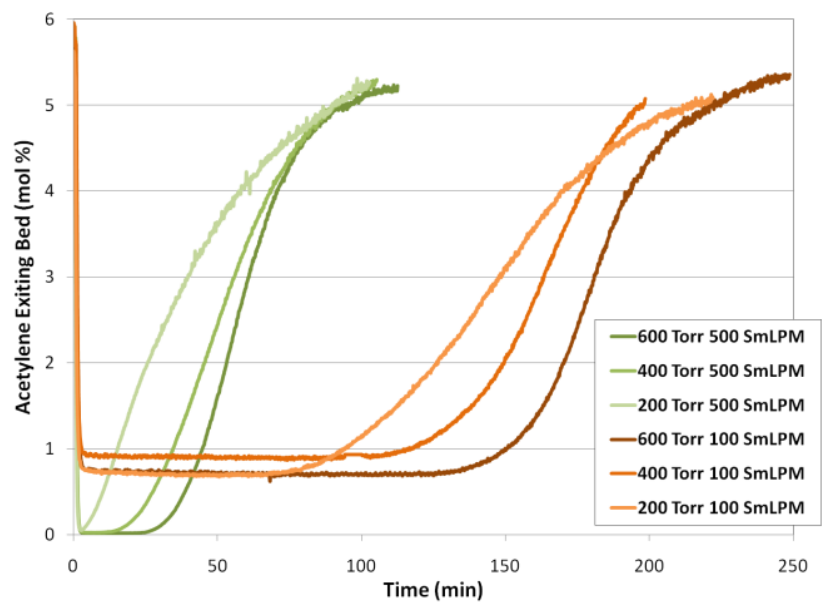

Figure 7. Mole Percent of Acetylene in Bed Exit Stream for Pressures at 600, 400, and 200 torr and Flow Rates of 500 and 100 SmLPM.

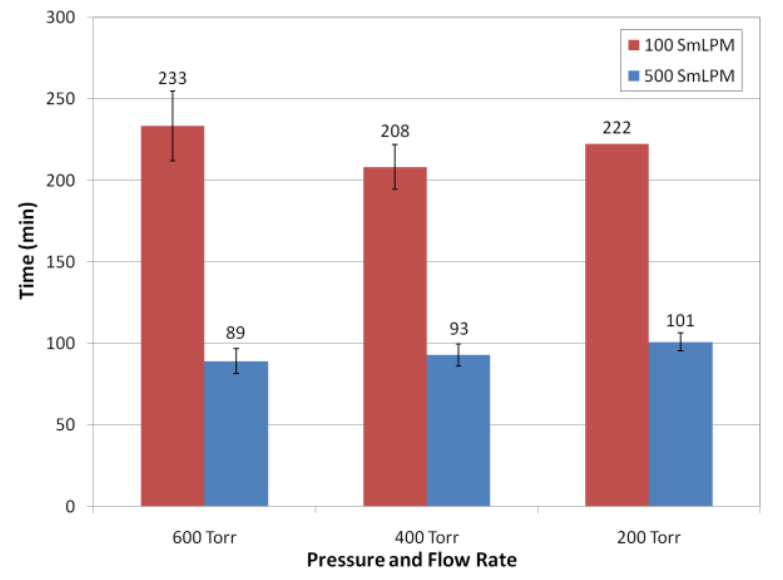

Figure 8. Time to Reach $90 \%$ Breakthrough on Zeolite 4A. Error bars indicate standard deviation.
The time to achieve initial breakthrough of acetylene (the point where the bed is no longer adsorbing all of the acetylene in the feed stream) was longer as pressure increased. This can be attributed to the greater capacity of Zeolite $4 \mathrm{~A}$ for acetylene at higher pressures.

Because it was not always clear where total breakthrough (point where the bed is no longer adsorbing any of the acetylene in the feed stream) occurred, $90 \%$ breakthrough was used to compare adsorption at different pressures. Time was calculated for $90 \%$ breakthrough by identifying the point when $90 \%$ of the total acetylene feed was passing through the bed. Figure 8 shows the average time to $90 \%$ breakthrough at each pressure and flow rate. As can be seen from the graph, time to $90 \%$ breakthrough was nearly independent of the pressure for the 4A zeolite. Breakthrough at $90 \%$ took much longer for the 100 SmLPM flowrate than for the 500 SmLPM flowrate. This is predictable due to the lower acetylene mass exposed to the bed at the lower flowrate.

Although the 4A sorbent bed showed significant acetylene adsorption at the conditions tested, intial breakthrough was observed very early in each test. The very gradual breakthrough of acetylene on 4A causes concern for a system in flight application. Following removal of acetylene, the remaining hydrogen and methane will be recycled to the CRA for additional reaction. There is currently no data for the effect of acetylene on the Sabatier reaction. Because a system based on 4A adsorption of acetylene would require a swing bed, at least two beds would always be required to allow adsorption on one and regeneration (desorption) of the other. If a zeolite $4 \mathrm{~A}$ bed were to be used in flight for acetylene separation, two options must be considered. The first option would be to have small beds but very short 
cycle times. Shortened cycle times increase the power required to adjust valves and heat the system for regeneration. This also adds to the stress of the system both mechanically and thermally. The second option would be to have larger beds that would provide greater capacity and result in longer time to breakthrough. However, increasing the size of each bed would result in greater mass and power requirements for the system.

\section{B. Acetylene Adsorption on HKUST-1 Microlith $\AA^{\text {Sorbent Bed }}$}

Testing of the HKUST-1 Microlith® sorption bed consisted of three trials with one repeat of each trial. Specific adsorption of acetylene on HKUST-1 is shown in Figure 9. The graph provides a comparison of adsorbed acetylene (mmols) per gram of HKUST-1. Averaged data for three runs at each pressure are shown with values listed at the top of each column. Progressive runs are shown in lighter shades, and error bars represent the standard deviation between the trial and its repeat. As seen from the data, the partial regeneration between runs was not shown to cause a significant decrease in adsorption capacity between runs.

The composition of the sorbent bed exit stream was evaluated (in mole \%) using the QMS. Each pressure showed a distinct curve regardless of the amount of acetylene adsorbed. Figure 10 compares exit stream acetylene composition (mol\%) during adsorption at each pressure. The adsorption data for each of these curves was taken from the first run of each of the three trials, although each run showed similar curves at a

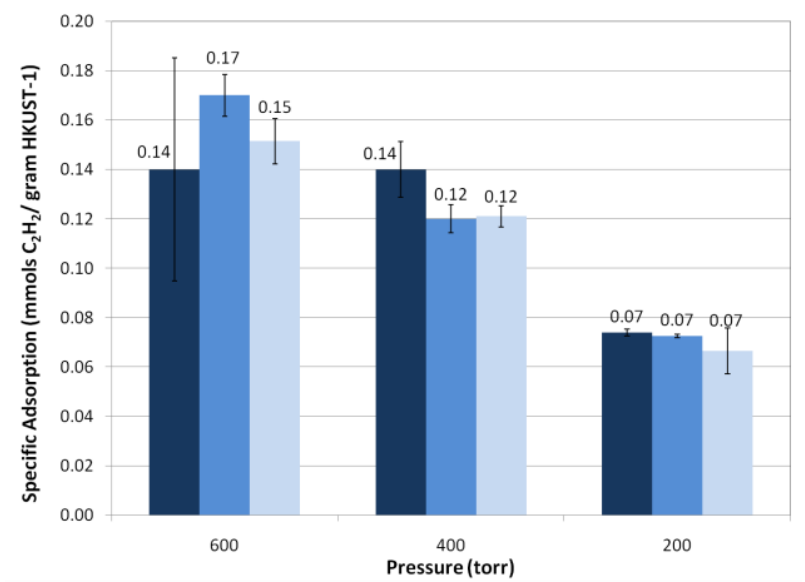

Figure 9. Specific Adsorption of Acetylene on HKUST-1 Microlith ${ }^{\circledR}$ at Multiple Pressures. given pressure. As can be seen from the graph, complete acetylene adsorption was never achieved with the HKUST-1 Microlith $®$ bed. Rather, at maximum removal of acetylene, the bed outlet still contained over 3\% acetylene at all pressures. This may be explained in three possible ways. First, It is possible that mass transfer was limited through the bed preventing maximum exposure of acetylene to the sorbent material. Second, it is possible that immobilization of HKUST-1 on the Microlith ${ }^{\circledR}$ structure altered the HKUST-1 material, limiting the capacity for acetylene. Finally, it is possible that a significant quantity of the HKUST-1 material was removed from the Microlith ${ }^{\circledR}$ due to thermal cycling from initial regeneration.

The areas above the curves shown in Figure 10 are indicative of the quantity of acetylene adsorbed during the test. This is more easily seen in Figure 11. As described in the previous section, 90\% breakthrough is reported because it was not always clear where total breakthrough (point where the bed is no longer adsorbing any of the acetylene in the feed stream) occurred. Again, this is indicative of the comparative capacities of acetylene on HKUST-1 at different pressures.

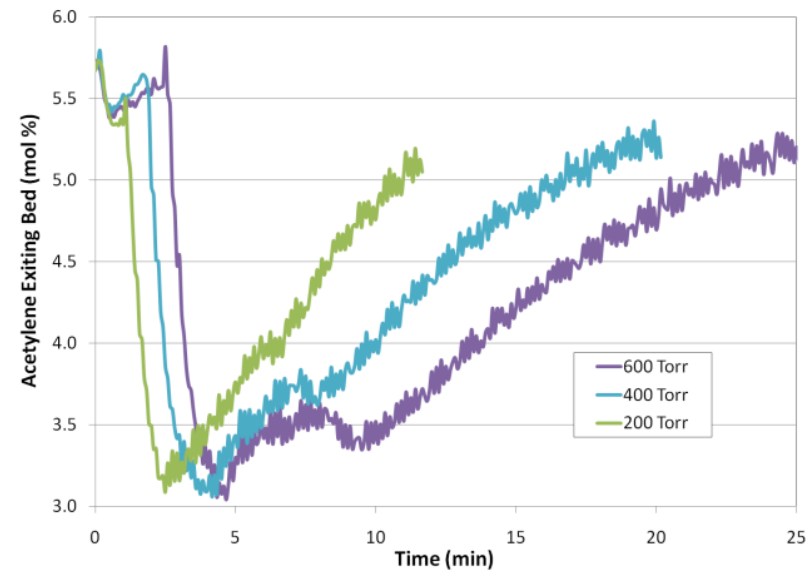

Figure 10. Mole Percent of Acetylene in Bed Exit Stream at 600, 400 and 200 torr.

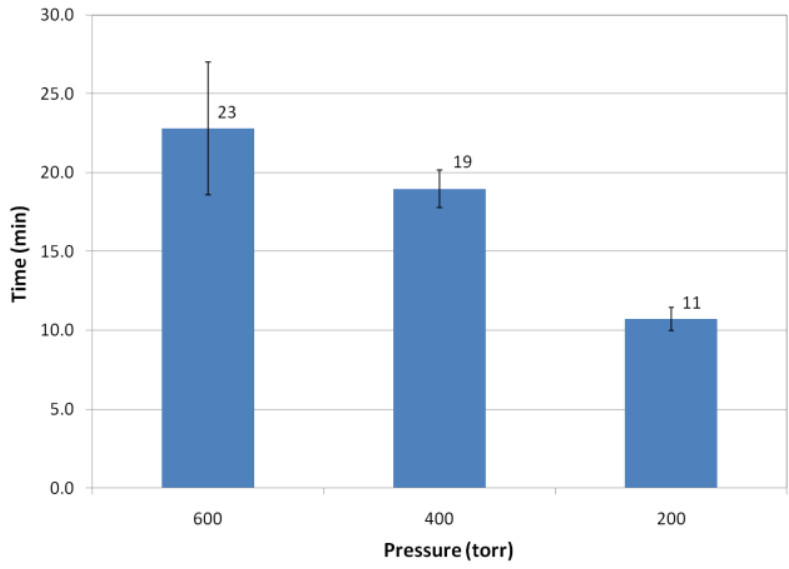

Figure 11. Time Required to Reach $90 \%$ Breakthrough of Acetylene on HKUST-1 Microlith®. Error bars indicate standard deviation.

8

American Institute of Aeronautics and Astronautics 


\section{HKUST-1 Packed Bed}

Testing of the HKUST-1 packed bed consisted of three trials each with three runs. Specific adsorption for the HKUST-1 packed bed is shown in Figure 12. Specific adsorption is shown in acetylene adsorbed (mmols) per gram of HKUST-1. Values for each run are shown above each column. Data at 600 torr and 200 torr showed a trend of decreasing adsorption between runs, but at 400 torr no such trend is observed. However, because only one run was completed for each data point, the difference in values may not prove to be statisically significant. Additional testing will be necessary before conclusions can be drawn.

During testing, the composition of the bed exit stream was measured with the QMS. Each pressure showed a distinct curve as shown in Figure 13. Acetylene exiting the bed never reached zero mole percent, meaning that $100 \%$ of the acetylene was never adsorbed. The HKUST-1 packed bed did maintain maximum adsorption for an extended amount of time for each pressure before gradually showing acetylene breakthrough. Although QMS calibration was checked before each day of testing, it is possible that levels $<1$

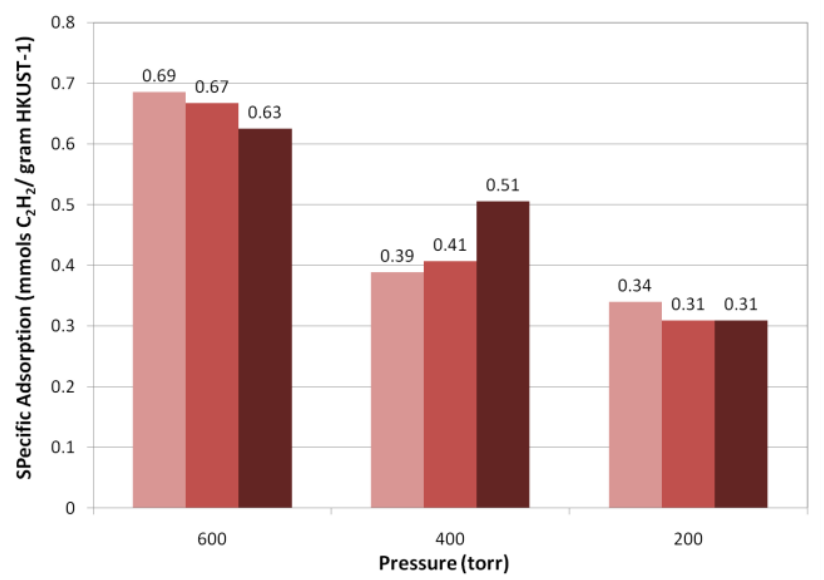

Figure 12. Specific Adsorption of Acetylene on Packed Powder HKUST-1. mol\% of acetylene were not accurately measured. Thus, it is possible that the observed values of $\sim 0.5 \mathrm{~mol} \%$ of acetylene, was actually zero. Again, additional testing will be necessary to determine the exact performance of the packed bed.

The areas above the curves in Figure 13 are indicative of the amount of acetylene adsorbed. This is better seen in Figure 14 which shows time to $90 \%$ breakthrough for the first run of each trial pressure. Time to $90 \%$ breakthrough was shorter for the HKUST-1 packed bed versus the Microlith® bed shown in Figure 11. This can be explained by understanding that the packed bed was tested at a higher flow rate (100 SmLPM versus 50 SmLPM for the Microlith ${ }^{\circledR}$ bed) and the packed bed reached a higher maximum adsorption versus the Microlith ${ }^{\circledR}$, as seen when comparing the breakthrough curves in Figure 13 and Figure 10.

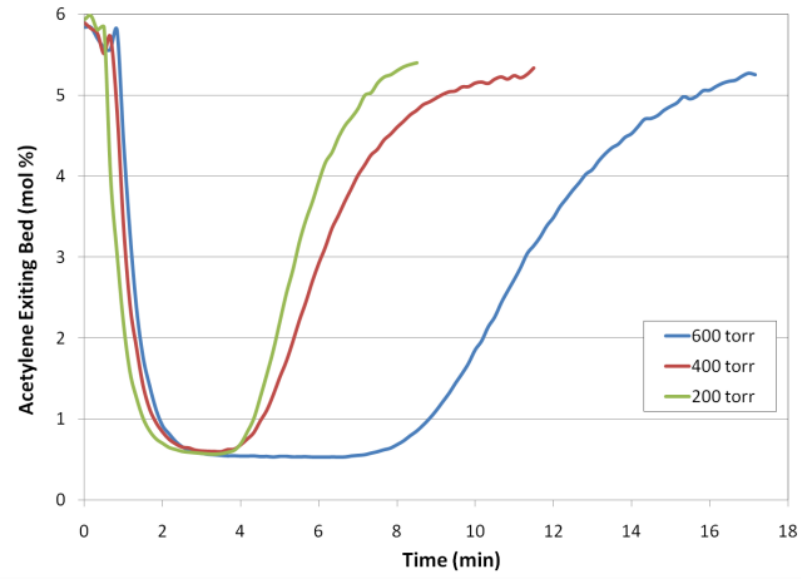

Figure 13. Mole Percent of Acetylene in Bed Exit Stream at 600, 400 and 200 torr.

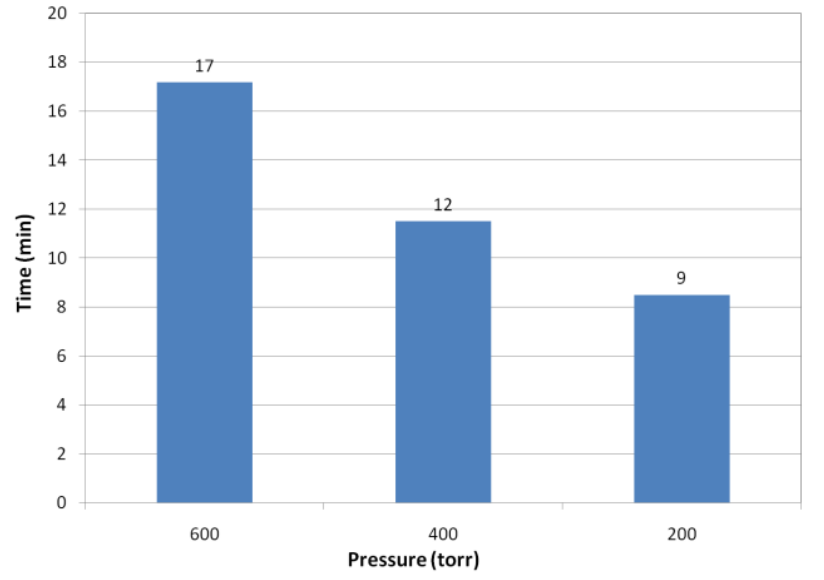

Figure 14. Time to Reach $90 \%$ Breakthrough of Acetylene on Packed HKUST-1.

\section{Sorbent Comparison}

Based on literature values for adsorption of acetylene on HKUST-1 and zeolite 4A, none of the beds performed as well as anticipated. This can best be seen graphically as shown in Figure 15. While adsorption on the zeolite 4A was in the general range of the reported values, the HKUST-1 was significantly lower than reported.

During preparation of the HKUST-1 Microlith ${ }^{\circledR}$, it was communicated by Precision Combustion, Inc. that significantly higher loading of the sorbent on the screen was possible. However, development of the bed in this testing was limited by time and resources. Future attempts will likely improve the sorbent loading and possibly 
improve the overall adsorption capacity of the Microlith® bed. The HKUST-1 packed bed showed better adorption capacity than the Microlith ${ }^{\circledR}$ bed, but still only a fraction of the literature value. Also, in application, a powder-based system is highly undesirable due to pressure drop and possible dusting. Therefore, HKUST-1 immobilization will be imperative if the material is to be used for acetylene separation in conjunction with the PPA and SDU.

\section{E. SDU Modified Feed Stream Test}

Based on the equilibrium design of the SDU reactor, it was predicted that the presence of methane in the hydrogen-feed would decrease the overall conversion of the reactants. This theory should have been supported by the observed decrease in reactor inlet temperature with increased methane, as shown in Figure 16. However, as can be seen in Figure 17, this was not the case. For all $\mathrm{H}_{2}: \mathrm{CO}_{2}$ ratios to the $\mathrm{SDU}$, there was no change in percent $\mathrm{CO}_{2}$ conversion. Similarly, there was no difference in water production rate or hydrogen conversion. This indicates that a recycle stream containing up to $15 \%$ methane may be fed from a PPA separation system directly back to the SDU without concern for decreased performance.

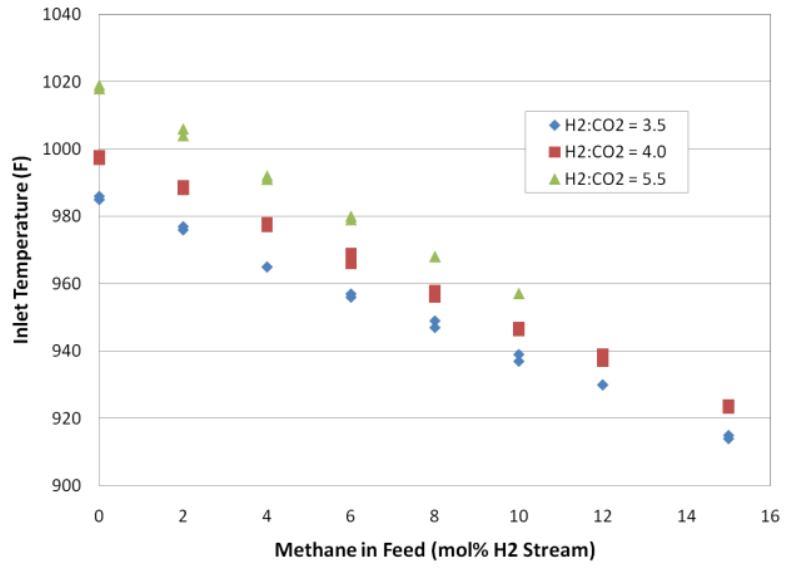

Figure 16. Effect of methane on SDU inlet temperature. Each data point was repeated once $(n=2)$.

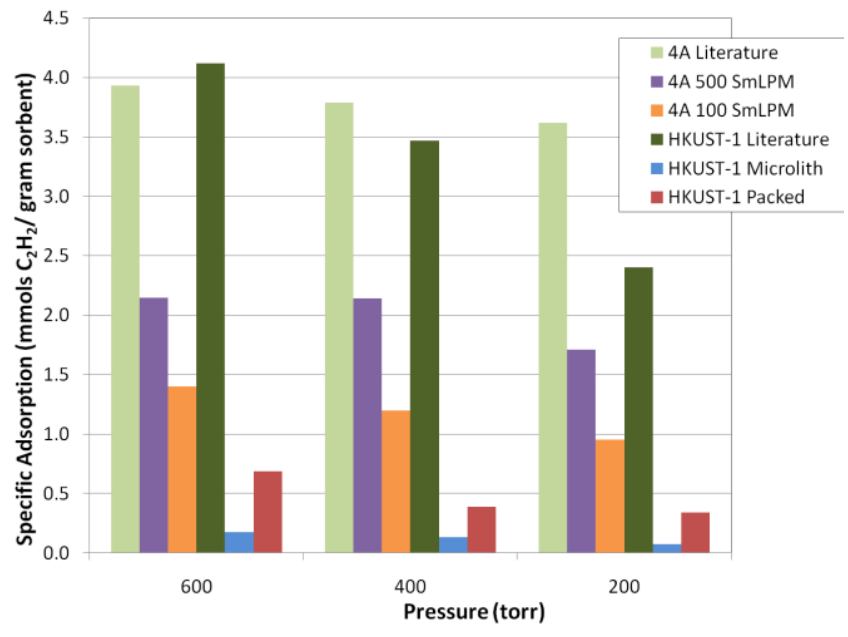

Figure 15. Literature and Empirical Specific Acetylene Adsorption for 4A and HKUST-1. Literature data taken at similar temperatures and identical pressures.

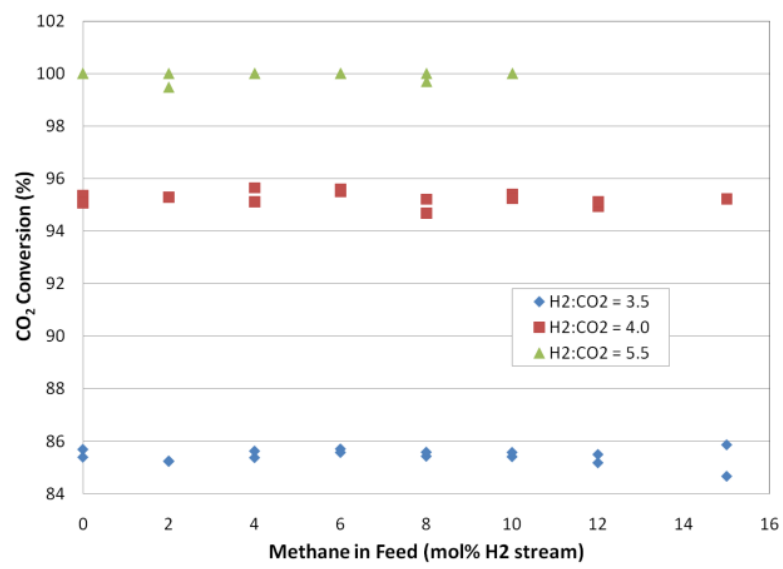

Figure 17. Conversion of $\mathrm{CO2}$ in SDU with a hydrogen feed stream containing methane. Each run was repated once $(n=2)$.

\section{Conclusion}

It is clear, based on the data presented here, that significant work is still necessary before an acetylene separation system can be realized for space flight. While the $4 \mathrm{~A}$ sorbent was capable of removing all acetylene, high regeneration temperature makes the material less attractive than HKUST-1. HKUST-1 did not provide complete acetylene removal necessary for a flight system, although a larger system or a system with better mass transfer may improve the results. Future work will involve analysis of the effect of a recycle stream directly from an acetylene separation unit on the performance of a Sabatier reactor as well as additional testing of both sorbents to explore alternative bed designs and/or immobilization techniques. Testing of different flow rates on each bed will be conducted to determine the effects of different flow regimes and effective residence time on acetylene adsorption. More consecutive runs with partial regenerations will be tested to determine the long term effects of partial regeneration on acetylene capacity. 


\section{Acknowledgments}

The authors would like to acknowledge Dr. Banglin Chen at the Unversity of Texas at San Antonio for the synthesis of HKUST-1 and his continued expertise in testing. They would also like to acknowledge Christian Junaedi and Precision Combustion, Inc. for their Microlith ${ }^{\circledR}$ coating efforts. The authors would like to thank Tom Williams and Kenny Bodkins for their ongoing support with the PPA test stand. Finally, the authors would like to thank the USRP internship program and those involved for their support in furthering research and education programs.

\section{References}

${ }^{1}$ Atwater, J. E., Wheeler, R. R., Jr., Hadley, N. M., Dahl, R. W., Carrasquillo, R. L., "Development and Testing of a Prototype Microwave Plasma Reactor for Hydrogen Recovery from Sabatier Waste Methane," 39th International Conference on Environmental Systems, SAE International, SAE 2009-01-2467, Savannah, Georgia, 2009.

${ }^{2}$ Abney, M.B., Miller, L.A., Williams, T., "Sabatier Reactor System Integration with Microwave Plasma Methane Pyrolysis Post-Processor for Closed-Loop Hydrogen Recovery," 40th International Conference on Environmental Systems, AIAA-20106474, Barcelona, Spain, 2010.

${ }^{3}$ Harper, R.J., Stifel, G.R., Anderson, R.B., "Adsorption of gases on 4A synethetic zeolite," Canadian Journal of Chemistry, Vol. 47, 1969, pp. 4661-4670.

${ }^{4}$ Chui, S. S.-Y., Lo, S. M.-F, Charmant, J. P. H., Orpen, A. G., Williams, I. D., "A Chemically Functionalizable Nanoporous Material $\left[\mathrm{Cu}_{2}(\mathrm{TMA})_{2}\left(\mathrm{H}_{2} \mathrm{O}\right)_{3}\right]_{\mathrm{n}}$," Science, Vol. 283, 1999, pp. 1148-1150.

${ }^{5}$ Lamia, N., Jorge, M., Granato, M.A., Paz, F.A.A., Chevreau, H., Rodrigues, A.E., "Adsorption of propane, propylene and isobutane on a metal-organic framework: Molecular simulation and experiment," Chemical Engineering Science, Vol. 64, 2009, pp. 3246-3259.

${ }^{6}$ Dathe, H., Peringer, E., Roberts, V., Jentys, A., Lercher, J.A., "Metal organic frameworks based on $\mathrm{Cu}^{2+}$ and benzene-1,3,5tricarbonxylate as host for $\mathrm{SO}_{2}$ trapping agents," Comptes Rendus Chimie, Vol. 8, 2005, pp. 753-763.

${ }^{7}$ Wang, Q.M., Shen, D., Bulow, M., Lau, M.L., Deng, S., Fitch, F.R., Lemcoff, N.O., Semanscin, J., "Metallo-organic molecular sieve for gas separation and purification," Microporous and Mesoporous Materials, Vol. 55, 2002, pp. $217-230$.

${ }^{8}$ Xiang, S., Zhou, W., Gallegos, J.M., Liu, Y., Chen, B., "Exceptionally High Acetylene Uptake in Microporous MetalOrganic Framework with Open Metal Sites," Journal of the American Chemical Society, Vol. 131, 2009, pps. 12415-12419.

${ }^{9}$ Liu, Y., Brown, C.M., Neumann, D.A., Peterson, V.K., Kepert, C.J., "Inelastic neutron scattering of $\mathrm{H}_{2}$ adsorbed in HKUST-1," Journal of Alloys and Compounds, Vol. 446-447, 2007, pp. 385-388.

${ }^{10}$ Khvostikova, O., Assfour, B., Seifert, G., Hermann, H., Horst, A., Ehrenberg, H., "Novel experimental methods for assessment of hydrogen storage capacity and modelling of sorption in Cu-BTC," International Journal of Hydrogen Energy, Vol. 35, 2010, pp. 11042-11051. 